\title{
A Rare Variant of the Great Cardiac Vein Draining Directly into the Superior Vena Cava
}

\author{
Ecaterina Dăescu ${ }^{a}$ Alexandra Enache $^{b}$ Dorina Sztika ${ }^{a}$ Delia Elena Zăhoi ${ }^{a}$ \\ ${ }^{a}$ Department of Anatomy and Embryology, Victor Babeș University of Medicine and Pharmacy Timișoara, \\ Timișoara, Romania; ${ }^{b}$ Department of Forensic Medicine, Victor Babeș University of Medicine and Pharmacy Timișoara, \\ Timișoara, Romania
}

\section{Significance of the Study}

- This paper presents a rare anatomical variant of the great cardiac vein, with regard to its drainage point and its relationships with the left coronary artery. This could be highly relevant to clinicians planning procedures that require venous access.

\section{Keywords}

Great cardiac vein · Coronary sinus · Superior vena cava · Dissection

\footnotetext{
Abstract

Objective: A routine dissection of the cadaver of a 67-yearold man revealed a very rare morphological variant of the great cardiac vein (GCV). Presentation: The vein originated in the upper third of the anterior interventricular sulcus, crossed the anterior interventricular artery superficially, ran beneath the circumflex artery, crossed the transverse pericardial sinus, and drained directly into the superior vena cava. Conclusion: This variant of the GCV is interesting due to its rarity. It is important to know about it for procedures that require venous access such as coronary surgery requiring retrograde cardioplegia, surgical ablation of aberrant conducting pathways, pacemaker insertion, and valve surgery.

(C) 2019 The Author(s)

Published by S. Karger AG, Basel
}

\section{Introduction}

Anatomically, the venous vascularization of the heart involves 2 systems: the greater cardiac vascular system which is the major collecting system, and the smaller cardiac vascular system formed by the small cardiac veins (Thebesian veins) and draining directly into the cardiac chambers [1]. The main collecting system (draining approx. $70 \%$ of the myocardium) comprises the tributaries and nontributaries of the coronary sinus, nearly all of which drain into the right atrium. Alongside the great cardiac vein (GCV), which is the longest and largest of the heart veins, the tributaries of the coronary sinus are the oblique vein of the left atrium, the posterior vein of the left ventricle, the middle cardiac vein, the posterior interventricular vein, and the small cardiac vein.

\begin{tabular}{ll}
\hline KARGER & $\begin{array}{l}\text { ( ) 2019 The Author(s) Karger } \\
\text { Published by S. Karger AG, Basel }\end{array}$ \\
E-Mail karger@karger.com & $\begin{array}{l}\text { This is an Open Access article licensed under the Creative Commons } \\
\text { Attribution-NonCommercial-4.0 International License (CC BY-NC) } \\
\text { (http://www.karger.com/Services/OpenAccessLicense), applicable to } \\
\text { the online version of the article only. Usage and distribution for } \\
\text { commercial purposes requires written permission. }\end{array}$
\end{tabular}




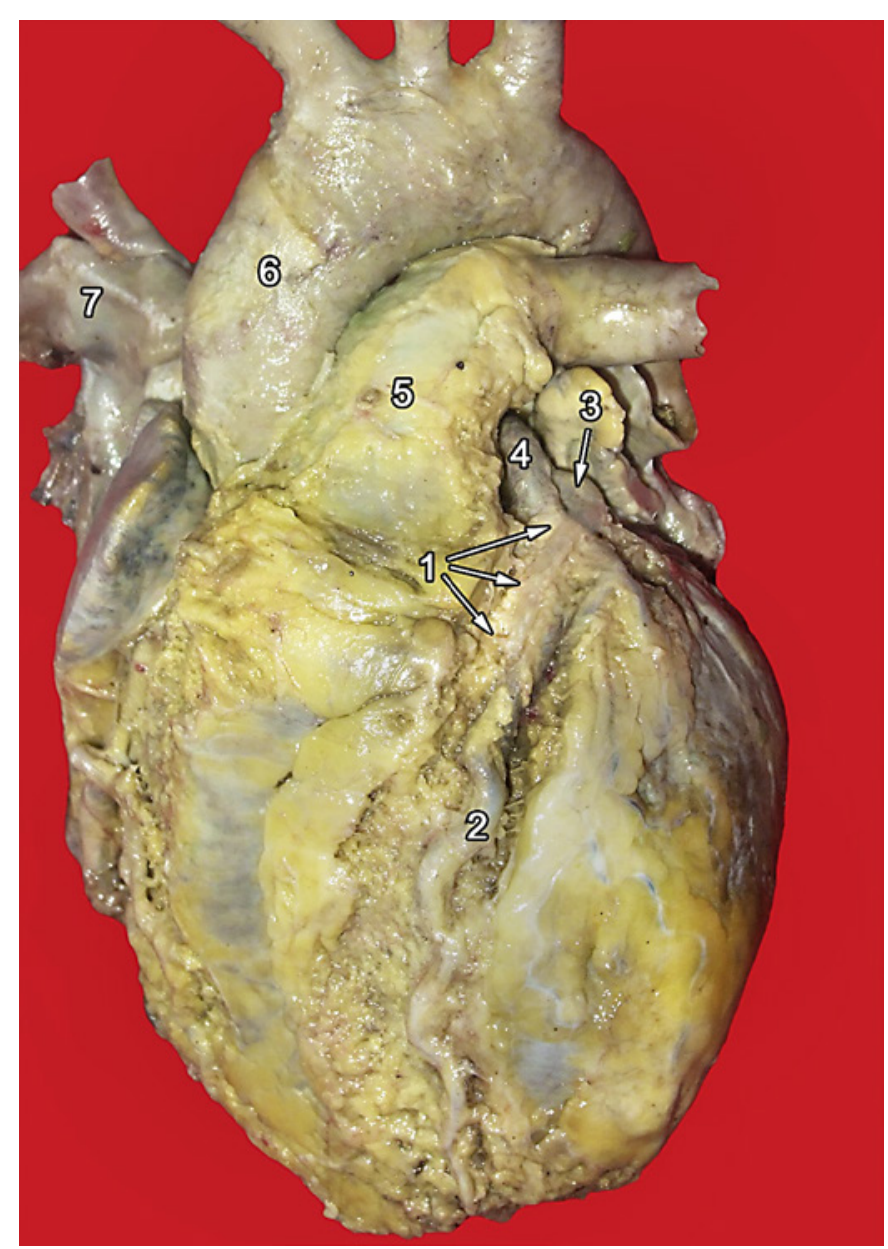

Fig. 1. Anterior view of the cadaveric heart showing the variant origin of the great cardiac vein (GCV): (1) GCV; (2) anterior interventricular artery; (3) circumflex artery; (4) left coronary artery; (5) pulmonary trunk; (6) ascending aorta; (7) superior vena cava.

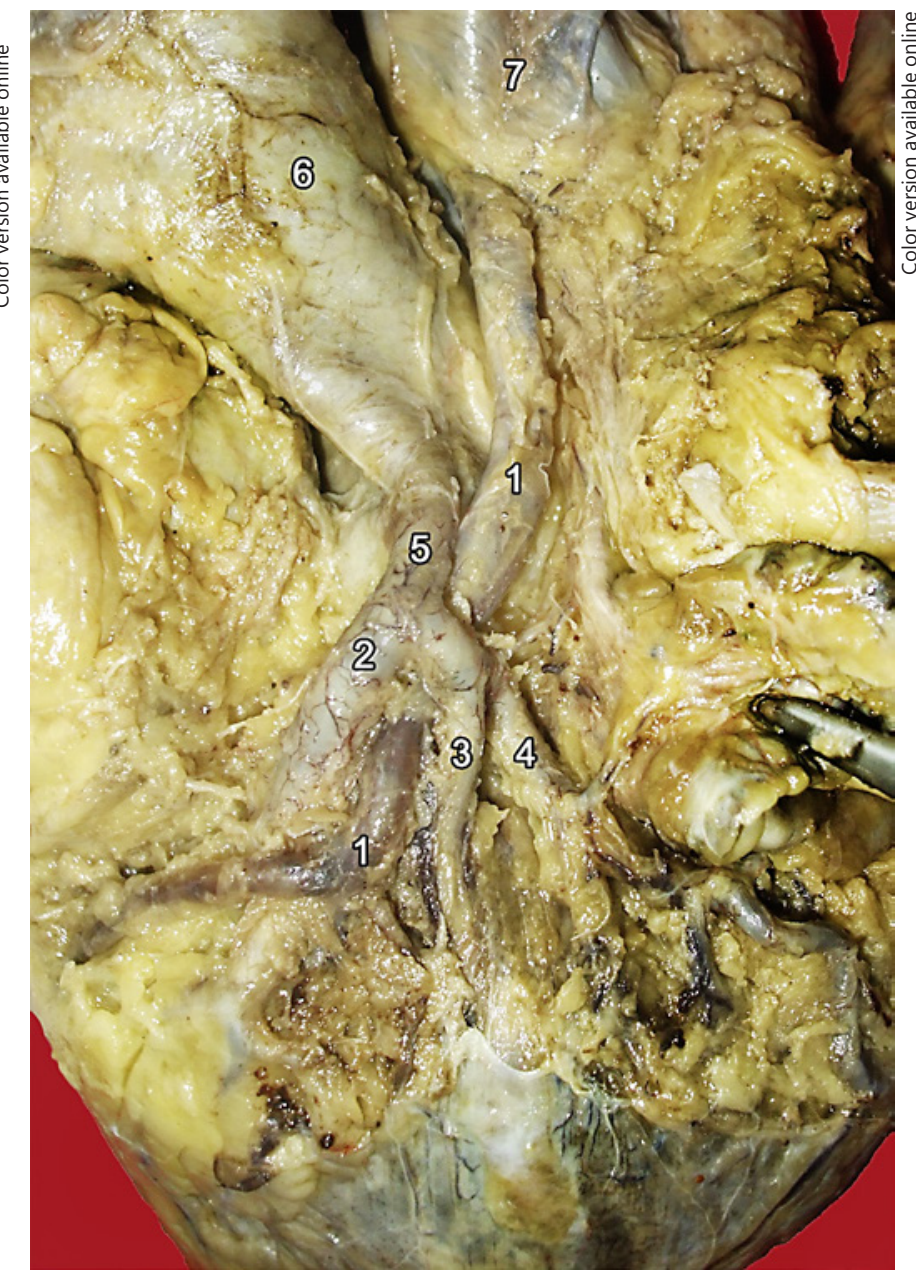

Fig. 2. Course of the great cardiac vein (GCV) through the transverse pericardial sinus and opening into the superior vena cava: (1) GCV; (2) anterior interventricular artery; (3) left marginal artery; (4) circumflex artery; (5) left coronary artery; (6) ascending aorta; (7) superior vena cava.

\section{Case Report}

A routine dissection of the cadaver of a 67-year-old male in the laboratory of the Department of Anatomy and Embryology revealed a very rare morphological variant of the GCV. The initial in situ dissection of the mediastinum was followed by that of the pericardium and greater vessels, which allowed for the removal of the heart from the thoracic cavity and subsequent examination. The isolation of the heart vessels revealed a GCV with unusual origin, course and, most notably, drainage point.

The GCV originated in the upper third of the anterior interventricular sulcus (AIVS) and followed an ascending course parallel and to the right of the anterior interventricular artery (AIA) (Fig. 1). Just below its point of origin, the GCV crossed the AIA and took a lateral and posterior course; it then ran below the left

marginal artery and the circumflex artery $(\mathrm{CxA})$, right at the origin of the latter in the left coronary artery (LCA), before reaching the transverse pericardial sinus. Within this, it ran to the posterior side of the ascending portion of the aorta, finally opening into the left side of the superior vena cava (SVC), at its point of drainage into the right atrium (Fig. 2). The coronary sinus was present in our case with no particularities.

\section{Discussion}

In this case, the GCV was much shorter and began in the upper third of the AIVS, a presentation we have not found in the literature. Studies show that, in most cases 
(58\%), the vein originates close to the apex of the heart or in the lower third of the AIVS. In a smaller percentage (20\%), it starts in the middle third of the AIVS [2]. The variability of the position of the GCV in relation to the AIA can cause difficulties when performing bypass procedures. In 2001, Gerber et al. [3] reported a presentation similar to that in our case in $12 \%$ of the studied cases. However, Ortale et al. [4] reported that, in $97 \%$ of cases, the GCV ran parallel and to the left of the AIA, so the 2 vessels did not intersect. In our case, on its course in the coronary sulcus, the GCV related differently to the arterial branches: it crossed the AIA superficially, and the CxA deeply. In most cases (60-70\%), the GCV crosses the branches of the LCA, lying superficially to the arteries [5]. The course of the GCV crossing the CxA deeply has been reported in $22 \%$ of cases [4] and in $27 \%$ of cases [2]. When lying deeply, the GCV can be compressed by a rigid artery, preventing the venous return of the blood.

Most frequently, in the coronary sulcus, the GCV forms the basis of the Brocq and Mouchet's arteriovenous triangle, which it delimits by crossing the 2 branches of the LCA. In this triangle, the vein lies superficially in $61 \%$ of cases [2]. In our case, the GCV lay deep and was interposed between the AIA and the origin of the CxA.

The rare cases related to the GCV drainage reported in literature can be grouped into 3 variants: directly into the right atrium, into the left SVC or into the SVC (the latter with 2 subcases, i.e., presenting or lacking a coronary sinus). The first case of a GCV draining into the SVC was reported by Bergman et al. [6] in 1988. In 2006, Praveen [7] reported a case in which the GCV opened into the right atrium, separately from the coronary sinus. Through image-based methods, Olearczyk et al. [8] and Lee et al. [9] each revealed a case in which the GCV drained directly into the SVC.

Animal studies have revealed that the precursors of cardiac veins are angiogenic buddings developed in the venous sinus. They form a capillary plexus from which the cardiac veins develop [10]. This theory might explain the predominant drainage of superficial cardiac veins into the venous sinus, and through it into the right atrium. The embryonic venous system, initially a symmetrical structure, undergoes a series of changes during the development of the atria. During week 8, a large anastomosis is formed that drains the blood from the left anterior cardinal vein into the right vein that will become the left brachiocephalic vein. Based on this, we can state that there are 2 major vascular networks in the heart. The GCV arises from the network of angiogenic buddings in the walls of the coronary sinus. The other anastomosis network, located between the anterior cardinal veins, forms the left brachiocephalic vein, at the same time as the SVC is formed. The morphological variant presented in this case can be explained by the intertwining of the 2 venous networks. The perturbation of the anterior cardinal venous system may cause the deviation from the course of the GCV. Additionally, the interaction of the GCV vein with the cardinal anastomosis plexus may cause the loss of the connection with the coronary sinus and the drainage of the GCV directly into the SVC.

\section{Conclusion}

In recent years, the clinical importance of the cardiac venous system has increased with the development of cardiac surgical methods based on venous access. The relationships of the GCV with the branches of the LCA and their crossings are important as they can prevent venous return when the vein lies deep. The drainage of the GCV directly into the SVC, bypassing the coronary sinus, may cause difficulties in certain procedures. In retrograde cardioplegia it may prevent the diffusion of the solution into the area drained by the GCV, and in biventricular cardiac pacing it may cause difficulties for electrode insertion.

\section{Statement of Ethics}

The dissection for this study was performed in accordance with the procedural and ethical standards set by the Department of Anatomy and the university's ethics committee.

\section{Disclosure Statement}

The authors have no conflicts of interest to declare. 


\section{References}

1 von Lüdinghausen $M$. The venous drainage of the human myocardium. Berlin: SpringerVerlag; 2003. https://doi.org/10.1007/978-3642-55623-4.

2 Pejkovic B, Bogdanovic D. The great cardiac vein. Surg Radiol Anat. 1992;14(1):23-8.

3 Gerber TC, Sheedy PF, Bell MR, Hayes DL, Rumberger JA, Behrenbeck T, et al. Evaluation of the coronary venous system using electron beam computed tomography. Int J Cardiovasc Imaging. $2001 \mathrm{Feb} ; 17(1): 65-75$.
4 Ortale JR, Gabriel EA, Iost C, Márquez CQ. The anatomy of the coronary sinus and its tributaries. Surg Radiol Anat. 2001;23(1):1521.

5 Saremi F, Mureșian H, Sánchez-Quintana D. Coronary veins: comprehensive CT-anatomic classification and review of variants and clinical implications. Radiographics. 2012 Jan-Feb;32(1):E1-32.

6 Bergman RA, Thompson SA, Saadeh FA. Absence of the coronary sinus. Anat Anz. 1988; 166(1-5):9-12.

7 Praveen IB. Great cardiac vein draining directly into the right atrium - A Case Report. J Anat Soc India. 2006;55:60-4.
8 Olearczyk BM, Menzies DJ, McNulty PH. Anomalous great cardiac vein. J Card Surg. 2008 Jul-Aug;23(4):408-9.

9 Lee HM, Sung YM, Lee JI. Anomalous great cardiac vein draining into the superior vena cava. Ann Thorac Surg. 2011 Jul;92(1):360.

10 Bernanke DH, Velkey JM. Development of the coronary blood supply: changing concepts and current ideas. Anat Rec. 2002 Aug; 269(4):198-208. 